\title{
Serum Interleukin 4 and 6 Levels Measured Using the ELISA Method in Patients with Acquired Bronchiectasis Compared to Healthy Subjects. An anti-inflammatory and pro-inflammatory relation
}

\author{
ANDREI LESAN ${ }^{1}$, MILENA ADINA MAN ${ }^{1, *}$, ROXANA MARIA NEMES $^{2}$, TUDOR HARSOVESCU², IOAN SORIN TUDORACHE ${ }^{2}$, \\ BEATRICE MAHLER BOCA ${ }^{3}$, CARMEN MONICA POP1 \\ Iuliu Hatieganu Unyversity of Medicine and Pharmacy, 8 Victor Babes Str., 400000, Cluj-Napoca, Romania \\ 2Titu Maiorescu University, Faculty of Medicine, 22 Dambovnicului Str., 031593, Bucharest, Romania \\ ${ }^{3}$ Carola Davila University of Medicine and Pharmacy, 8 Eroii Sanitari Blvd, 050474, Bucharest, Romania
}

\begin{abstract}
Evaluation of the inflammatory response based on the Interleukin 4 and Interleukin 6 levels in patients with acquired bronchiectasis (non-cystic fibrosis) and healthy controls. The study was conducted on a group of 77 subjects, divided into 2 lots: the first lot consisting of 57 patients with acquired bronchiectasis objectified by Computed Tomography and 20 healthy individuals. The serum Interleukins 4 and 6 levels were measured using the ELISA biochemical spectrophotometry test. The results are significant from a statistical point of view, especially when it comes to the mean value of Interleukin 4 that was much higher in the control lot. Interleukin 4 is a proinflammatory cytokine and therefore we can draw the conclusion that to some extent bronchiectasis can be associated with an immunodeficiency disorder prior to the pathology itself or it can be caused by the pathology. Future research is open in this field for the analysis of interleukin levels in bronchioloalveolar lavage compared to serum levels.
\end{abstract}

Keywords: bronchiectasis, non-cystic fibrosis, interleukins 4 and 6, anti-inflammatory, pro-inflammatory

Bronchiectasis is an incurable pulmonary disorder, characterised by permanent and abnormal dilation of the lung airways (bronchi). Bronchiectasis develops as a consequence of genetic and environmental factors, but their etiopathology remains unclear [1]. It represents an irreversible lung disease caused by recurrent bacterial infections and chronic inflammation of the intermediate bronchi (at least $2 \mathrm{~mm}$ in diameter) [2]. This pathology represents a significant cause for respiratory morbidity but it is, in the same time, a common disease. Muco-ciliary clearance is affected and this increases the vulnerability of airways to colonization by pathogens [3]. Among the numerous causes that determine impaired muco-ciliary clearance, tobacco exposure is described as favoring decreased anti-infectious defense mechanisms and this is certified by biochemical study of its biomarkers[4]. The actual prevalence of this disease remains unknown given its sub-diagnosis due to the lack of appropriate technical equipment or lack of addressability in specialized medical units, nevertheless it has been increasingly recognized in the past 2-3 decades. Considering the fact that this is a sub-diagnosed pathology, it is very difficult to determine its social-economic impact on the population. Still, it is a clear that this is a significantly underestimated disease $[5,6]$. Patients exhibiting this pathology often experience chronic cough accompanied by expectorations, progressive dyspnea, decreased lung capacity, recurrent exacerbations (through bacterial infections) and especially decreased quality of life and life expectancy [7-11]. The treatment protocol is not yet a well determined one and continues to be mainly empirical, butall-in-all patients keep exhibiting symptoms and worsening of the lung functions. Choosing the right antibiotic for the treatment of bronchiectasis exacerbations is mainly empirical and relies on the most likely pathogen or in ideal conditions on knowledge of the sputum cultures from previous hospital stays [12]. Respiratory morbidity, such as mostly often encountered tuberculosis or other non-tuberculous infections and the overall quality of life are the most important aspects when it comes to patients with bronchiectasis and in this regard, it becomes clear that more studies are needed to improve these [13-17]. In the past years, there has been an increased interest in discovering new methods to detect bronchiectasis, but especially in assessing its evolution.

For this purpose, an attempt has been made to trace certain non-specific and specific inflammatory markers in the inflammatory relation occurring in patients with bronchiectasis. Recent studies have shown that inflammatory cytokines, secondary to infections and recurrent inflammations, play an important role in the pathogenesis of bronchiectasis, either in the acceleration of the development of bronchiectasis or in stopping their evolution [18-22]. The most promising results in the pathology of bronchiectasis seem to involve inflammatory cytokines [23]. Interleukins are signaling proteins or molecules belonging to the group of cytokines and which are mostly secreted by lymphocytes but can also be secreted in small quantities by monocytes, macrophages and endothelial cells. Their synthetization occurs in CD4 lymphocytes and leads to the formation and development of $B$ and T lymphocytes, but also of hematopoietic cells [24]. In bronchiectasis, activation of innate immune responses causes the releases of chemokines which increasing of the cellular inflammatory infiltrate including IL-6, IL-8, and leukotriene B4 [25]

Persistent airway inflammation and interleukin (IL)6 is among the mediators implicated in regulation of inflammation in bronchiectatic airways. [26]

Interleukins are a subgroup of cytokines and can be classified as pro- or anti-inflammatory (pro-inflammatory interleukins IL-1 $\beta$, IL-6, and IL-8;) The bronchiectatic airway epithelium can produce an exaggerated pro- 
inflammatory cytokine response due to infectious stimuli . [27]

The main aim of our study was to assess the inflammatory response based on the Interleukin 4 and Interleukin 6 levels in patients with acquired bronchiectasis (non-cystic fibrosis) and healthy controls

\section{Experimental part}

Two groups were formed for the purpose of this study. The first group included 57 patients with non-cystic fibrosis bronchiectasis diagnosed by Computed Tomography (gold standard for the diagnosis of bronchiectasis) and the second group included 20 control subjects with no previously diagnosed bronchiectasis pathologies. The subjects were selected from the patients of the ClujNapoca Lung Clinic (Clinica de Pneumoftiziologie Leon Daniello Cluj-Napoca). The factors considered for each subject were: age, gender, smoker or non-smoker status. The subjects filled out a form enquiring on the quality of life, namely a modified nCAT.

After a detailed analysis of the medical history, blood samples were taken to perform complete blood counts and serum biochemistry. Sputum samples were taken for bacteriological examination, which included: BAAR, GRAM, BK culture and aerobic culture. Bronchial aspiration fluid to perform GRAM stain and BAAR microscopic examination for Mycobacterium Tuberculosis, were also performed for the groups that did not show any bacterial growth from the spontaneous sputum sample.

The next step referred to paraclinical investigations: spirometry to determine possible ventilatory disfunctions, exhaled nitride oxide, 6 min walk test and chest X-ray. Computed Tomography was carried out after the customary testing performed in the clinic. This investigation was performed in all the patients with suspected bronchiectasis, using multidetector $C T$, which generates more accurate results than classic Computed Tomography. After studying the results of the imaging investigation, only the before-mentioned 57 patients remained in the study.

It is worth mentioning that these clinical and paraclinical investigations are carried out independent of this study, which is an observational studyand does not condition the diagnostic or therapeutic conduct in case of these patients. The patients diagnosed with bronchiectasis, based on the above-mentioned investigations, were given the option to be part of the study. After obtaining their informed consent (approved by the ethic committee of the university), we continued with blood sampling for specific and specialized investigations over the course of the current research. This did not compel to or imply any financial involvement of the patients.

At least 2 phials of $4 \mathrm{~mL}$ whole blood have been sampled from each patient. These were kept at room temperature for at least $30 \mathrm{~min}$ ( $60 \mathrm{~min}$ optimum, but with a uniform interval for all the samples). After 30 (namely 60 ) min, the blood underwent centrifugation for 10 minutes at 1000 rotations per minute, according to the specifications of the manufacturer of the BoosterTM interleukin kits. The resulting supernatant (serum), which needs to amount to a total of $3 \mathrm{~mL}$ (optimal amount $4 \mathrm{~mL}$ ) is stored in two phials at -20 degrees $C$, for at least one months, during which sufficient samples have been gathered for long-term storage at -70 degrees $C$, until all the samples were gathered for processing.

The method used in this study for interleukin-4 and - 6 was spectrophotometric ELISA. Two devices from different manufacturers were used for this purpose, in order to get the best accuracy of the results. The spectrophotometers used were Biotek and Sunrise. This method was preferred in order to allow a comparison between the two readings of the same plate with 96 wells. Conveniently, the results obtained with each of the devices, with two readings for each, were identical. Thus, all the micro test tubes (wells) were appropriate and none of the kits was unusable. It should also be noted that each of the two interleukins has been analyzed in duplicate, for the same reason - so that the results are as accurate and precise as possible.

The used ELISA (Enzyme-linked ImmunosorbentAssay) technique represents a molecule (proteins, carbohydrates, etc.) detection method suing enzyme-conjugation antigen/ antibodies complexes. This is a highly sensitive method and it is expressed in $\mathrm{pg} / \mathrm{ml}$. It may be qualitative or quantitative and uses monoclonal antibodies and enzymes. For this study, the results were expressed in $\mathrm{pg} / \mathrm{mL}$ and the results were quantitative. The enzymes represent biochemical catalyzers, compounds that increase the speed of chemical reactions occurring in biological systems, without being consumed in the process. Thus, we may infer that the intensity of the generated reaction (namely the staining of the micro test tubes) is directly proportional to the quantity of enzymes in the respective biological product. The biochemical enzymes used in this measurement are: peroxidase, alkaline phosphatase, glucose oxidase and G6PH. The biological samples to which this technique is applicable are: serum, plasma, urine, stool sample, synovial fluid, CSF and bronchoalveolar lavage fluid. For our study however, we used only serum from the patients with acquired bronchiectasis and healthy control subjects.

The SigmaPlot 12.0 program was used for statistical analysis and the significance was demonstrated with a P value $<0.05$. For the assessment of the studied data, in addition to the descriptive statistical methods we used the independent-samplest-testfor normal distribution variables and the Mann-Whitney $U$ test for variables that were not normally distributed. Logistic regression analysis was used to assess the significant inflammatory reaction in the observed subjects. The Chi-Square test was used to compare the anti-inflammatory and pro-inflammatory response in both groups and the odds ratio (relative risk) with a confidence interval of $95 \%$ was calculated to determine risk factors.

\section{Results and discussions}

Obstructive lung diseases are characterized by a chronic inflammatory response, especially in the small airways and lung parenchyma, which in its turn is characterized by a high macrophage, neutrophil and T lymphocyte count. This can be observed locally and can easily be substantiated by bronchoalveolar lavage. What we aim for is to observe whether there is a systemic inflammatory response (both pro- and anti-inflammatory) within the bronchiectasis pathology, the central elements used for this purpose being interleukin-4 and -6. Demographic characteristics of the study and the control groups were describe in table 1.

In order to better understand the anti-inflammatory and pro-inflammatory processes, the results are divided into two categories: the results for interleukin- 4 and the results for interleukin-6, as follows:

Interleukin-4 is a pro-inflammatory interleukin. Table 2 reveals the average value for interleukin- 4 in patients with bronchiectasis, compared to the results from the serum of the studied control subjects and its standard deviation.

By applying the t-test to determine the statistical value of these results we obtained a $p$ value $<0.001$. This shows 


\begin{tabular}{|c|c|c|c|}
\hline & Number [\%] & & \\
\hline & Patients $(n=40)$ & Control $(\mathrm{n}=20)$ & \\
\hline Age (years) & $23.40 \pm 4.32$ & $21.60=1.96$ & 0.082 \\
\hline Education & & & \\
\hline Illiterate & $2[5]^{-}$ & $2[10]$ & 0.159 \\
\hline Primary school & $15[37.5]$ & $12[60]$ & \\
\hline High school & $14[35]$ & $6[30]$ & \\
\hline University & $9[22.5]$ & - & \\
\hline Income level & & & \\
\hline Low & $23[57.5]$ & $9[45]$ & 0.641 \\
\hline Medium & $15[37.5]$ & $10[50]$ & \\
\hline High & $2[5]$ & $1[5]$ & \\
\hline Smoking & & & \\
\hline Smoker & $13[32.5]$ & $2[10]$ & 0.058 \\
\hline Nonsmoker & $27[67.5]$ & $18[90]$ & \\
\hline
\end{tabular}

Tabel 1

DEMOGRAPHIC CHARACTERISTICS OF THE STUDY AND THE CONTROL GROUPS

Table 2

AVERAGE IL4 VALUES AND STANDARD DEVIATION

Fig. 2. Plate after staining. Antigen/antibody color reaction ed bronchiectasis compared to healthy control subjects. The highest value obtained in subjects with acquired bronchiectasis was 1127 , while the highest value in healthy control subjects was only 400.5. The minimum value determined for the studied groups was 45.18 in patients with acquired bronchiectasis namely 14.28 in healthy control subjects. These results are represented in figure 1.

\section{IL-4 ELISA}

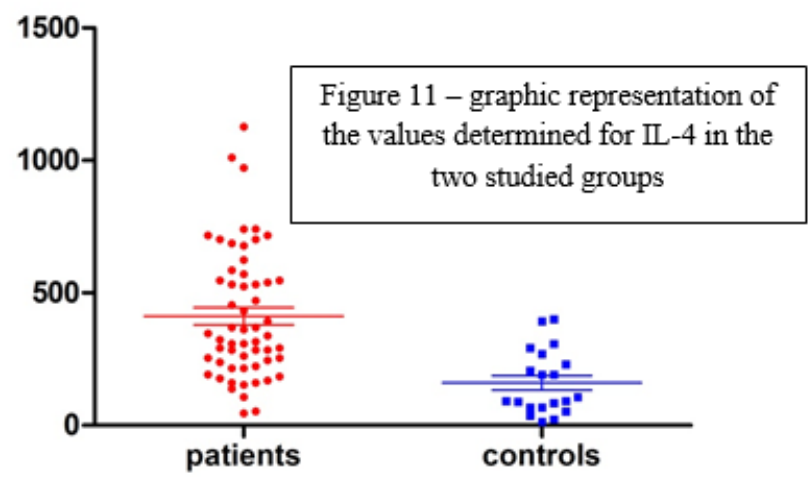

Fig. 1. Graphic representation of the values determined for IL-4 in the two studied groups

There is a clear statistic difference in the values of interleukin-4 in the patient group (acquired bronchiectasis substantiated by CT investigations) and the control group represented by healthy subjects (or who at least exhibit no bronchiectasis).

For a better visual perception of the antigen/antibody reaction, relevant for the ELISA technique, we can refer to figure 2 - a photo taken during the preparation phase of the plate interpreted by the spectrophotometer.

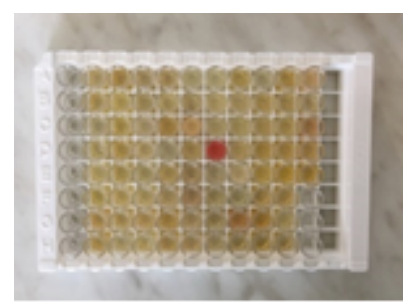

Interleukin-6 is anti-inflammatory par excellence and table 3 reveals the difference between the average values determined in both studied groups. The average value is different in the two groups, but greater difference can be observed in terms of the minimum and maximum values obtained in these two groups. The results obtain from IL-6 measurements reveal higher values in patients with acquired bronchiectasis as compared to the healthy control subjects, so that anti-inflammatory reaction is encountered in patients with this pathology.

The graphic representation of these values is represented as a scatter plot, in figure 3. This portrays the difference between the two groups most accurately.

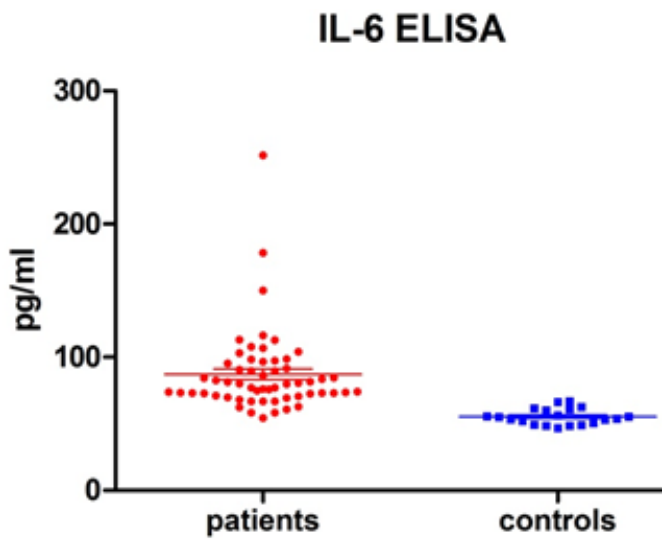

Fig. 3. graphic representation of the IL-6 values for the two groups

\begin{tabular}{|c|c|c|}
\hline & $\begin{array}{c}\text { Group 1 - patients with } \\
\text { bronchiectasis }(\mathrm{n}=57)\end{array}$ & $\begin{array}{c}\text { Group 2 - healthy } \\
\text { control subjects }\end{array}$ \\
\hline Average IL6 value $(\mathrm{pg} / \mathrm{ml})$ & 87.11 & 55.35 \\
\hline Standard deviation & 30.88 & 6.000 \\
\hline Minimum value IL6 $(\mathrm{pg} / \mathrm{ml})$ & 54.40 & 46.99 \\
\hline Minimum value IL6 $(\mathrm{pg} / \mathrm{ml})$ & 251.7 & 66.96 \\
\hline
\end{tabular}

Table 3

AVERAGE, MAXIMUM AND MINIMUM VALUES, AS WELL AS THE STANDARD DEVIATION BETWEEN THE TWO GROUPS FOR IL-6 
Using the t-test we determined that this comparison is statistically relevant, the $p$ value in this comparison being $<0.001$.

The specialized literature has been researched for the purpose of this paper, but we did not find any work dealing with these two interleukins in patients with acquired bronchiectasis. A comparison between the results obtained for the two interleukins is irrelevant for the simple reason that these deal with two faces of the same coin that don't ever meet and hereby we refer to the pro-inflammatory and the anti-inflammatory aspects of bronchiectasis in a separate manner.

Bronchiectasis is a pathological entity characterised by inflammation and/or recurrent infections. This pathology has the property to activate an innate response which will determine a very significant inflammatory response, this response is translate in the serum by the release of inflammatory proteins and cellular infiltrates such as IL-6, IL-8, leukotriene B4, etc. [25]. This is the proinflammatory response in the natural evolution of bronchiectasis, which can be very important in acquired forms of bronchiectasis.

As demonstrated in COPD -associated with smoking, which is the main cause for this pathology -bronchiectasis, too, is characterised by chronic pulmonary inflammation, which is why the serum level of interleukins is also elevated. Some studies considered only COPD when studying the relationship between CRP (C-reactive protein) and IL-6 plasmatic levels and have shown that these can connect some COPD phenotypes to the elevated levels of these acute phase proteins. Of course, it is impossible to exclude all of the non-disease related factors: lifestyle and/or socioeconomic conditions $[28,29]$. Thus, if there is an association between different phenotypes of COPD and the plasmatic levels of acute phase proteins, why not in bronchiectasis as well? Why wouldn't it be possible to predict the exacerbation of bronchiectasis based on the plasmatic levels of acute Interleukins?

Some studies have show $n$ that there is a direct relation between IL-4 levels and the mucus-secreting glands, in the sense that these cytokines stimulate the hypersecretion of mucus. IL-4 is a multifunctional cytokine that influences the mucus-secreting tissue, as well as the B lymphocytes [30]. Therefore, if the IL-4 level is significantly increased in COPD and bronchiectasis it can also be increased in bronchiectasis, which is also a mucus-secreting disease and can act at least as a marker if not as a veritable tool for prognosis.

There have been extensive studies regarding IL-4, IL13 , as well as T-helper-2 in diseases such as COPD, chronic bronchitis and even asthma. Such studies have shown that these interleukins are key proteins in the allergic response. Even though the vast majority of these studies are on asthma and the inflammatory response, however there is also a relation between the smoking behaviour in COPD and chronic bronchitis and the plasmatic levels of these interleukins [31]. Although studies did not show a significant increase of the IL-6 and IL-8 levels in exsmokers with COPD in association with the severity and clinical profile[32, 33,34], there is still an overall increase of the inflammatory cytokines in the chronic inflammatory diseases including bronchiectasis. The relation between these proteins and pulmonary inflammatory diseases, as well as the smoking behaviour gives us a good overall perspective on the possibility of cytokine involvement in the evolution of the bronchiectasis. There is a study showing that IL-4 induces gobletcell metaplasia via a direct effect on airway epithelial cells, so there is an important pulmonary effect of chronic IL-4 increased levels[35].
The predictive role of plasmatic interleukins is somewhat limited and at this moment cannot be used as a marker in the prognosis of bronchiectasis. On the other hand, when we take into consideration the relation between the inflammatory plasmatic cytokines and the ones measured from the bronchioloalveolar lavage, in patients with bronchiectasis, the predictive capabilities increase significantly [36]. Bearing all these in mind, the need for further studies in the direction of bronchoalveolar lavage emerges and shows great promise for the diagnosis and prognosis of acquired bronchiectasis.

\section{Conclusions}

The values obtained for IL-4 are significantly higher in patients with acquired bronchiectasis as compared to the healthy control subjects. The sensitivity of the method used is especially high in terms of the quantitative results obtained for IL-4 (sensitivity), however specificity is the one that should be demonstrated. Up to this moment, there are no studies encountered in the specialized literature referring to inflammatory reactions based on two interleukins - the pro- and anti-inflammatory ones.

In case of IL-6, too, the spectrophotometric measurements of the antigen/antibody reaction (ELISA) are higher in patients with bronchiectasis, but still the difference is not as great as in case of IL-4. It is known that interleukin is an anti-inflammatory cytokine.

The general conclusion that can be draw $n$ from this study at this time is that patients with bronchiectasis exhibit a much more significant pro-inflammatory reaction compared to the anti-inflammatory reaction and compared tode healthy control subjects, who are considered to be the standard for this determination.

Thus, this study infers that patients with bronchiectasis exhibit a certain degree of immunosuppression, which is why the pro-inflammatory reaction becomes so significant. At this time, we cannot know whether this immunosuppression is the one causing the bronchiectasis pathologies or at least leading to their aggravation or bronchiectasis was the one leading to the immunosuppression.

For a better understanding of this inflammatory phenomenon, based on pro- and anti-inflammatory interleukins altogether, we recommend the performance of serum and bronchioalveolar lavage fluid analyses, both in patients with acquired bronchiectasis and in healthy control subjects.

\section{References}

1.AYHAN G, TAS D, et al. Relation between inflammatory cytokine levels in serum and bronchoalveolar lavage fluid and gene polymorphism in young adult patients with bronchiectasis. J Thorac Dis. 2014;6(6):684-93.

2.BARKER AF, Bronchiectasis. N. Engl. J. Med. 2002: 246: 1383-93. 3.LOEINGER MR, WELLS AU, HANSELL DM, CHINYANGANYA N, DEVAIAN A, MEISTER M, WILSON R, Mortality in bronchiectasis: a long-term study assessing the factors influencing survival. Eur. Respir. J. 2009: 34: 843-849

4. TROFOR, A., PETRIS, O., TROFOR, L., MAN, M.A., FILIPEANU, D., MIRON, R., Biochemistry in assessing tobacco exposure - smokers versus non-smokers -correlations with clinical practice. Rev. Chim. (Bucharest), 68, no. 5, 2017, p. 1002-1006

5.WEYCKER D, EDELSBERG J, OSTER G, TINO G, Prevalence and economic burden of bronchiectasis. Clin. Pulm. Med. 2005; 12: 205209.

6.NEMES RM, POSTOLACHE P, TINTILA A, MIHALTAN FD, PETRARIU FD. Aspects of physician - patient communication in the program of smoking cessation. Medical-Surgical J ournal 2015; 119(1):23-30 
7.PASTERU MC, BILTON D, HILL AT, British Thoracic Society Bronchiectasis non-CF Guideline Group. British Thoracic Society guideline non-CF bronchiectasis. Thorax 2010; 65(1): 11-58.

8.TANTU, MM , MAN, GM, PAUNESCU, A., et al., Corelations Between the Use of Medical Substances and the Incidence Infections Produced by Clostridium Difficile Species, Rev.Chim. (Bucharest), 69, no. 11, 2018, p. 3001-3005

9.POP, C.S., POMOHACI, C., IUCU, R., et al., Prevalence of alchohol related medical problems among excessive and heavy drinking women in a Romanian Emergency Hospital. Revista de Cercetare si Interventie Sociala, 2015; 51: 41-45.

10.OTELEA, M.R., ARGHIR, O.C., ZUGRAVU, C., NAGHI, E., ANTONIU, S., RASCU, A., Lung function and quality of life in workers with chemical and dust exposure. Rev. Chim (Bucharest), 69, no.2, 2018, p.346-349. 11.GOLLI ,A.L, NITU, F.M., BALASOIU, M., LUNGU, M.A,, OLTEANU, M., NEMES, R.M., FORTOFOIU, M., RUSU, E., OLTEANU, M., Antibiotic Resistance Pattern of Bacterial Pathogens in Elderly Patients Admitted in the Intensive Care Unit, Rev. Chim (Bucharest), 69, no.2, 2018, p.3433-3438

12.PASTEUR MC, BILTON D, HILL AT, Guideline for non-CF Bronchiectasis. Thorax. 2010; 65(1)

13.MAN MA, NITU MF, STRAMBU L, FLORESCU C, STREBA CT, TROFOR A Tuberculous constrictive pericarditis complicated with tuberculous mediastinitis - case report. Romanian Journal of Morphology \& Embryology. 2016; 57(1):237-242

14.MAN MA, ARGHIR OC, MAN S, STREBA CT, OLTEANU M, NITU M. Fatal paradoxical cryptic miliary tuberculosis and immune reconstitution disease in a young non-HIV immunocompromised male patient: case report with autopsy findings. Rom J Morphol Embryol, (2014);55(2): 453-457.

15.NATHAN AM, BRUYNE Al, et al, Review: Quality of life in Children with Non-Cystic Fibrosis Bronchiectasis, Front Pediatr. 2017; 5:84.

16.CONSTANTIN B, POSTOLACHE P, CROITORU A, NEMES RM. Occupational bronchial asthma - clinical and epidemiological aspects. J ournal Of Environmental Protection And Ecology 2015; 16(2): 517-520 17.NEMES RM, POP CS, CALAGIU D, DOBRIN D, CHETROIU D, JANTEA $P$, et al. Anemia in Inflammatory Bowel Disease More Than an Extraintestinal Complication. Revista medico-chirurgicala a Societatii de Medici si Naturalisti din lasi. 2016;120(1):34-39.

18.BOYTON JR, ALTMANN DM, Bronchiectasis: Current Concepts in Pathogenesis, Immunology, and Microbiology, Annual Reviews of Pathology: Mechanisms if Disease, 2016; 11:523-554

19.GOLLI, A.L, NITU, M.F., TURCU, F., POPESCU, M., CIOBANUMITRACHE. L., OLTEANU, M., Tuberculosis remains a public health problem in Romania Int J Tuberc Lung Dis 2019;23(2): 226-231

20.NEMES RM, IANOSI ES, POP CS, POSTOLACHE P, STREBA T, OLTEANU M, GOLLI AL, OLTEANU M, NITU MF. Tuberculosis of the oral cavity. Romanian Journal of Morphology and Embryology, 2015; 56(2), 521-525.

21.IORADACHE PD, MATESD, GUNARSSON B, EGGERTSSON HP, SULEM P, BENONISDOTTIR S, CSIKI IE, RASCU S, RADAVOI D, URSU R, STAICU C, CALOTA V, VOINOIU A, JINGA M, ROSOGA G, DANAU R, SIMA SC, BADESCU D, SUCIU N, RADOI V, MATES IN, DOBRA M, NICOLAE C et al. Identification of Lynch syndrome risk variants in the Romanian population. J Cell Mol Med. 2018; 22(12): 6068-6076.
22.RUSU, E., SARBU, I., MITACHE, M., MOLDOVAN, H., VASSU, T., PELINESCU, D., Ultrastructural changes of Candida albicans species induced by the presence of sodium diclofenac. Rev. Chim (Bucharest), 68, no.11, 2017, p.2566-2569

23.HO JC, TIPOE G, et al, In vitro study of regulation on IL-6 production in bronchiectasis, Respiratory Medicine. 2014; volume 98, Issue 4:334341.

24.TORRADO E, COOPER AM, Cytokines in the balance of protection and pathology during mycobacterial infections, Adv Exp Med Biol. 2013; 783:121-140

25.KING TP., The Role of the Immune Response in the Pathogenesis of Bronchiectasis BioMed Research International Volume 2018 26.HO JC, TIPOE G, ZHENG L, LEUNG TM, TSANG KW, In vitro study of regulation of IL-6 production in bronchiectasis. Respiratory medicine, 2004; 98(4): 334-341.

27.GARTH J, BARNES J, KRICK JS Targeting Cytokines as Evolving Treatment Strategies in Chronic Inflammatory Airway Diseases Int. J. Mol. Sci. 2018; 19: 3402;

28. YANBAEVA DG, DENTENER MA, SPRUIT MA, et al. IL6 and CRP haplotypes are associated with COPD risk and systemic inflammation: a case-control study. BMC Medical Genetics. 2009; 10:23.

29.NITESCU M, FURTUNESCU FL, OTELEA $M$, et al. Prevalence of metabolic syndrome parameters in a Romanian population of young adults. Revista Romana de Medicina de Laborator, 2012; 20(3): 21-28 30.ZHU J 1, QIU Y, VALOBRA M, QIU S, MAJUMDAR S, MATIN D, DE ROSE V, JEFFERY PK. Plasma cells and IL-4 in chronic bronchitis and chronic obstructive pulmonary disease. Am J Respir Crit Care Med. 2007;175(11):1125-1133.

31.MIOTTO D1, RUGGIERI MP, BOSCHETTO P, CAVALLESCO G, PAPI A, BONONI I, PIOLA C, MURER B, FABBRI LM, MAPP CE. Interleukin-13 and -4 expression in the central airways of smokers with chronic bronchitis. Eur Respir J. 2003;22(4):602-608.

32.DE MORAES MR, DA COSTA AC, CORREA KDE S, JUNQUEIRAKIPNIS AP, RABAHI MF. Interleukin-6 and interleukin-8 blood levels' poor association with the severity and clinical profile of ex-smokers with COPD. Int J Chron Obstruct Pulmon Dis. 2014;9:735-743.

33.IANOSI ES, POSTOLACHE P, MACOVEI LA, SZATHMARY M, SZASZS, NEMES RM, JIMBOREAN G. Smoking Cessation in COPD Patients by a Selective Partial Nicotinic Agonist. Revista de Chimie , 2018 ; 69(7): 1766-1769

34.IANOSI, E.S., DANTES, E., CSIPOR, A., SZATHMARY, M., SOCACI, A., RUSU, E., NEMES, R.M., Enhancing Education for Smoking Preventing and Smoking Cessation in Medical Personnel A measure for a better health. Rev. Chim (Bucharest), 69, no.10, 2018, p.2725-2727.

35.DABBAGH K, TAKEYAMA K, LEE HM, UEKI IF, LAUSIER J A, NADEL JA. IL 4 induces mucin gene expression and goblet cell metaplasia in vitro and in vivo. J Immunol 1999; 162:6233-6237

36.AYHAN G, TAS D, YILMAZ I, OKUTAN 0, DEMIRER E, AYTEN 0, KARTALOGLU Z.J Thorac Dis. 2014;6(6):684-693.

Manuscript received: 10.07 .2018 